\title{
The Effect of Emotional Intelligence on Job Satisfaction: Applied Study in the Jordanian Telecommunication Sector
}

\author{
Abdul Azez Badir Alnidawy ${ }^{1}$ \\ ${ }^{1}$ Business Administration Department, Al-Zaytoonah University, Amman, Jordan \\ Correspondence: Dr Abdul Azez Badir Alnidawy, Head of Business Administration Department, Al-Zaytoonah \\ University, Amman, Jordan. Tel: 962-79-998-7302. E-mail: Dr54azezalnidawy@yahoo.com
}

Received: February 24, 2015

Accepted: March 16, 2015

Online Published: May 7, 2015

doi:10.5430/ijba.v6n3p63

URL: http://dx.doi.org/10.5430/ijba.v6n3p63

\begin{abstract}
Human resource is one of organization important elements, Managers have big responsibility to achieve organization desired objectives, Therefore they have to use their abilities effectively with employees, employees play important role in reflecting of company image, the affect of their emotions using and regulation in work place have important fact in their job satisfaction, this study to measure the impact of the emotional intelligence of mangers and employees on their job satisfaction. A questionnaire was designed to gathering data and it's included ( ) questions. The sample of the study are (300) employees. After the data collected the proper statistical analysis was applied. The result showed that the emotional intelligence had big impact on the job satisfaction in organization. This study also, recommended a set of conclusions and recommendations that achieve the purpose of this study.
\end{abstract}

Keywords: emotional intelligence, job satisfaction, human resources

\section{Introduction}

Emotional intelligence core and important factor for life success, and psychology also playing a role interaction in the relation between the managers and their employees in Organization (Fauzy Bin Yacco, \& Md Shah, 2012). Also, (Psilopanagioti and Niakas, 2012) stated that emotional intelligence is very important for organization service sector outcome (Gunavathy \& Ayswarya, 2011).

Explored that job satisfaction is important for both levels (organization and individual) also Job performance have same importance, Individuals should competent in control their emotions under pressure and stress and through constraints (Psilopanagioti et al, 2012) find these contributing good understandings of emotional parameters that affect the process of work in are increasing in the service and its quality.

\section{Study Methodology}

\subsection{Problem Statement}

Emotion is a part of person humanity. The interactions between employees and mangers actions and emotions in organization have affect in their doing business. This issue has impact direct or indirect relationship between others. Some action could consider right but it might understand as wrong from others, but in contrary some actions Wrong and could understand right from others (Sener, Demirel, \& Sariak, 2009). People with high emotional and social capacity, can take them under control, understand and manage emotions of others expertly are more advantageous both in their private and professional lives.

The problem of the study was formed methodically as following main question:

Is there an effect of Emotional Intelligence on the Job Satisfaction in the Jordanian Telecommunication Sector?

\subsection{The Importance of Study}

- The scientific importance of the study:

This study is considered a new reference to the researchers and academics, as it offers the famework theory and practice of the emotional intelligence and job satisfaction. Also, this study may constitute a basis where the researchers move from it to a more spacious field towards research and investigation about the emotional intelligence and job satisfaction on this sector and other different sectors. 
- The practical importance of the study

The importance of study to the managers of Jordanian telecommunication companies sector.

This study provides a contemporary reference which shows the administrators and the decision makers in the Jordanian telecommunication companies sector the effect of emotional intelligence and job satisfaction in their organizations as they make use of it in generating new ideas which helps them to invest the human resources which will be positively be reflected on their organizations.

- The importance of the study to the employees in the Jordanian telecommunication companies sector.

This study suggests an imagination to the employees of the Sector of the Jordanian communications sector of the effect of their emotional on them which will help them to generate new ideas which can be discussed with their mangers to reach the desired goals of their organizations.

- The economic importance of the study:

This study helps to discover one of the most important sources of the organization which helps it to perform its mission and to show the ideal way to lead this source and this source is represented in the employees which when it is leaded in an ideal way will prompt it to do its work at the best manner to reach the best conclusions in addition to that it motivates it to generate new ideas and to develop the old ideas through which the organization can introduce the best and the new to the present clients and to attract new clients which will help the organization to exploit the available opportunities in the market and that will positively be reflected on the economical indications of the organization represented by the market share/ growth average/ the profits of the organization.

\subsection{Objective of the Study}

The main objective of the study is to understand and explain the effect of Emotional Intelligence on the Job Satisfaction and to provide knowledge of how the Emotional Intelligence effect on employee's Job Satisfaction, also, make to provide knowledge of how the worker Job Satisfaction according to demographic factors. From the other side to define how Emotional Intelligence effect on employees for telecommunication sector. Finally to provide knowledge of workers type (managers and employers) most effect from emotional intelligence on the job satisfaction.

\subsection{The Model of Study}
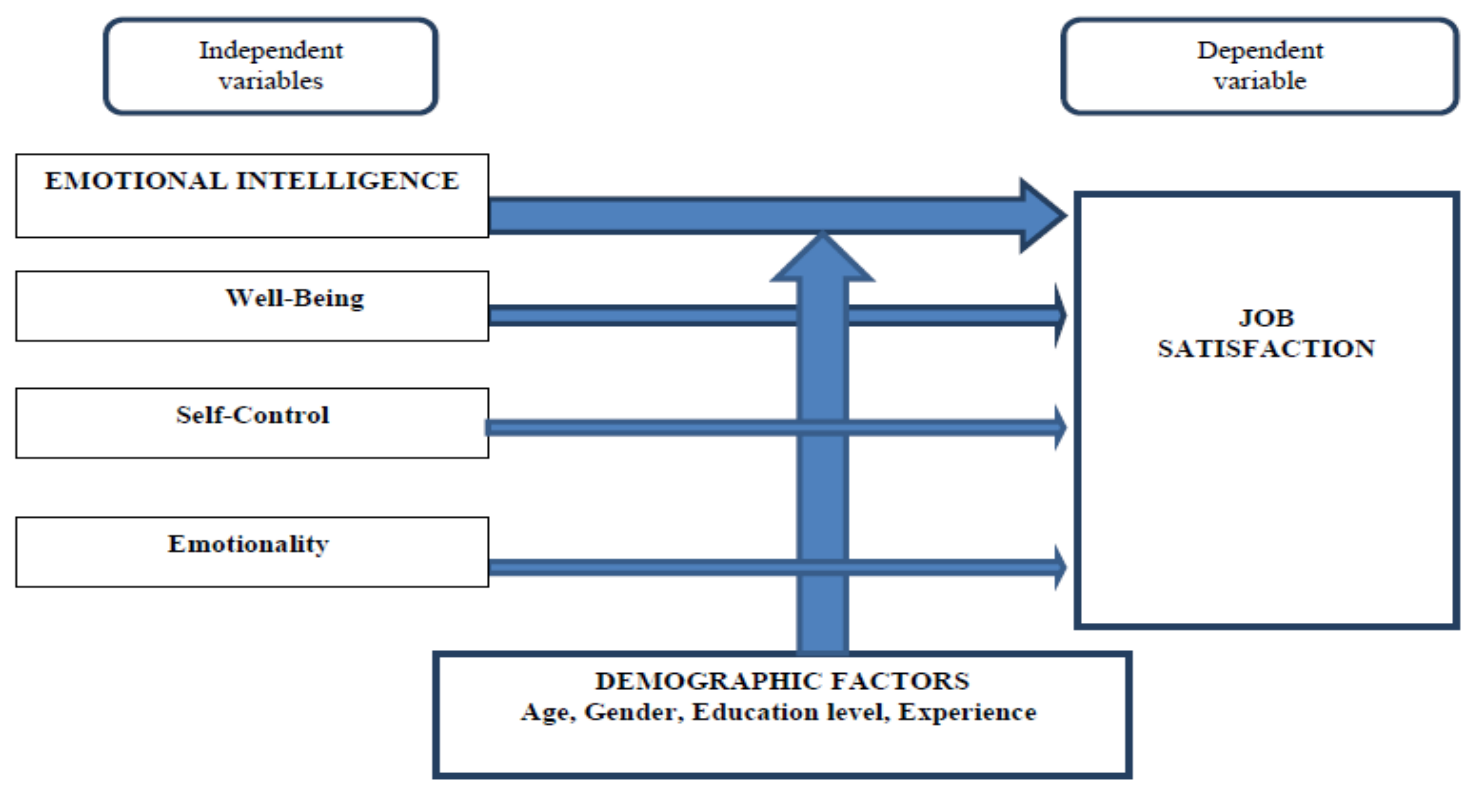

Source: Design by researcher based on (Chadha \& Singh, 2011) 


\subsection{Hypothesis}

The hypotheses of study was formulated based on the problem of the study, its objectives, its model and the study hypothesis are represented by the following:

The main first hypothesis

Ho1: There is no statistically significant affect for Emotional Intelligence on the Job satisfaction in the telecommunication companies.

Ho1-1: There is no statistically significant affect for Well-being on the Job Satisfaction.

Ho1-2: There is no statistically significant affect for Self-control on the Job Satisfaction.

Ho1-3: There is no statistically significant affect for Emotionality on the Job Satisfaction.

\subsection{Society and the Sample of the Study}

The society of the study consists of all the employees in the sector of the Jordanian telecommunication companies which are (3) three companies, depending on the statistical formulas in specifying the size of the sample, so it was limited to (300) sample and it was distributed as the following:

Table 1. The number of the distributed questionnaire

\begin{tabular}{lc}
\hline The company & Number of distributed questionnaires \\
\hline Zane Company & 100 \\
\hline Orange Company & 100 \\
\hline Umneiah company & 100 \\
\hline Total & 300 \\
\hline
\end{tabular}

\subsection{Methods of Collecting Information}

The methods of collecting information consisted of two parts:

- The first part

The researcher conducted a review and survey of the different theoretical and field studies related to the emotional intelligence and job satisfaction. They reviewed books and the scientific magazines, Master and $\mathrm{PhD}$ thesis, in addition to the reliable information from the Internet.

- The second part

A questionnaire was developed to reflects the effect of the on the elements of the emotional intelligence and job satisfaction and it was made use of the previous questionnaires in this subject and it was exposed before a number of the arbitrators to be sure of the veracity of the content where necessary modifications have been conducted on the questionnaire paragraphs, then distributed on the study sample who were the staff of the Jordanian telecommunication companies, and Likert quintuple scale was used to measure the content of the questionnaire as follows:

(1- for the degree, strongly agree) (2- For the degree, agree) (3-for the degree, neutral) (4- For the degree, disagree) (5- For the degree, strongly disagree)

The statistical methods and statistical package was used (spss) as its serves the objectives, the problems and the hypotheses of the study.

\subsection{Definitions of the Study Variables}

The study included many of the main variables as explained by the model of the study and it was necessary to explain these variables, so can the reader understand their variables and here is an explanation for these variables:

* Emotion: It is a progressive activity of organization in response to perceived dead lock, that usually involves in integrated collection of physiological responds, subjective to feelings and connected to cog native activity (Psilopanagioti, 2012).

* Intelligence: It is the ability to acquire and apply knowledge and skills (Htto/www.Oxford dictionaries.com, 2014). 
* Emotional Intelligence: It is the ability to monitor one's own and others feelings and emotions to discriminate among them and to use information to guide one's thinking and action (Mayer and Warner, 2004)

* Job Satisfaction: its describes effective response to your job and the attitudes the important of job satisfaction attribute that frequently measured by companies through rating scale, employee's reaction to their work. Also, it is an attitude, which is "an evaluation or evaluative judgment made with regard to an attitudinal object (Kumari and Pandev, 2011).

\section{The Theoretical Framework}

(Mayer JD, 1997) Defined the emotional intelligence as "The ability to monitor one's own and others feelings and emotions to discriminate among them and to use information to guide one's thinking and action." (Jorfi et al., 2012) Emotional intelligence core and important factor for life success, and psychology also playing a role interaction in the relation between the managers and employees. (Brackett, Mayer, \& Warner, 2004) stated that's ability to recognizing the one's own emotions and others' emotions, to express accurately both (own and others emotions) to enhance social relationships and personal. Emotional Intelligence term used in several literatures((Greenspan, 1989); (Leuner, 1966); (Payne, 1986)) and the formal model issue of Emotional Intelligence definition by (Mayer JD, 1997) many models of Emotional Intelligence emerged. (Carter, 2005) He indicates that Emotional Intelligence is referred commonly EQ (Emotional Quotient), ability of control, manage, and aware of ones and others emotions. There are two aspects:

1). Understanding yourself, own responses, goals, and behavior.

2). Understanding others and their feelings.

\subsection{Emotional Intelligence Models}

\subsubsection{Ability Model}

Salovey and Mayer's (1990) earliest study on emotional intelligence. This model conceptualizes of emotional intelligence in form of intelligence or mental ability (Cherniss, 2010). Salovey and Mayer first defined of emotional intelligence as "the ability to monitor one's own and others' feelings and emotions, to discriminate among them and to use this information to guide one's thinking and actions" (Mayer, 1990, p. 189).

They conceptualized of emotional intelligence as a skill to process the emotionally loaded information, this the reason to called this model of information processing of Emotional intelligence (Petrides \& Furnham, 2000), the refinement research, (Mayer \& Caruso, 2000). Later they adapted their definition for emotional intelligence that included four parts:

- Expression \& Perception the expression of the ones emotions, through physical state analyzing, feelings and thoughts. Also this factor includes appraising on accuracy the others' emotions.

- Thought \& Emotions: focus in the use of emotions to help in emotional \& intellectual growth. This compromise of using emotions in:

1). Weighing emotions against one another.

2). Direct attention.

3). Priorities thinking.

4). As a memory or judgment aid.

- Analyzing \& Understanding: labeling and Recognizing emotions, identifying relationships between them by using the reasons. Regulation: The highest and the important level of emotional intelligence, this the ability to express and regulate the feelings of your owns emotions and to other emotions.

\subsubsection{Mixed Model}

Include parts of ability of emotional intelligence and personality traits (Van Zyi and Dec, 2012) stated the emerging of mixed of emotional intelligence models strongly related to personality as conceptualized of it, and the constructs correlations between each of them.

This interfere could create a conceptual confusion with referring to the real nature of relationship between personality and mixed model of emotional intelligence.

(Van Zyl \& de Bruin, Dec 2012) concluded that the mixed model of emotional intelligence and general personality such as interpersonal functioning, internal constraint, dominance and positive affectivity. These general personality 
have a little focal aspects on the human behavior.

- The Bar-On model of emotional-social intelligence

Bar-On developing a model to answers the question, "Why are some individuals more able to succeed in life than others? (Mayer et al., 2000). He conceptualization of emotional intelligence put forth by the ability model and expanded on it by adding in certain concepts that are related to personality, resulting in his mixed of emotional intelligence model.

According to Bar-On, "emotional-social intelligence is a cross-section of interrelated emotional and social competencies, skills and facilitators that determine how effectively we understand and express ourselves, understand others and relate with them, and cope with daily demands" (Bar-On 2006). The definition includes five separate components as following:

(1) Intrapersonal skills

(2) Interpersonal skills

(3) Adaptability

(4) General mood

(5) Stress management

Each of these which can be sub-divided into competencies and number of skills.

\subsubsection{Trait Emotional Intelligence Model}

(Petrides, 2001) was one of the earlier researchers to give al clear picture for a complete differentiation between emotional intelligence models. Also (Mayer et al., 2000) proposed a differences between mixed models and ability, this did not identify the reason of why they should be split it into two groups, the psychometric implications of assessing maximum vs. typical performance.

Self-report measure is better for typical performance under mixed and trait emotional intelligence models. While the maximum performance assessments are mainly used as a measure of cognitive ability for ability of emotional intelligence model.

(Mayer et al., 2000) indicated that there is a possibility to measure the self-report measure with a ability of emotional intelligence model. Also, (Petrides, 2001) examined as empirically \& theoretically invalid.

The trait emotional intelligence model (otherwise known as trait emotional self-efficacy) is as a part based on the dispositions included in earlier emotional intelligence models and on successful traits (Cherniss, 2010). In this sense, (Petrides \& Furnham, 2001) attempted to "systematize and evaluate an approach that largely exists already" through an exhaustive content analysis of emotional intelligence models and existing literature. Their ultimate goal was to include those aspects that were common to many models, while excluding those that appeared in only a single model (petrides, furnham, \& mavroveli, 2007).

Job Satisfaction was initiated in 1959 with the purpose of studying job satisfaction among a representative cross section of workers in the United States. One specific goal of these studies was to relate job satisfaction to measurable company and community characteristics and to characteristics of the individual worker" (http://www.sba.oakland.edu).

(Weiss, 2002) argues that treating these concepts and definitions contain job satisfaction as interchangeable, researchers missed out when they focus on interesting research regarding the processes that behind the each conceptualization for the construct and separate causes. He stated that the correct definition of job satisfaction is an attitude, which is "an evaluation or evaluative judgment made with regard to an attitudinal object".

(Kumari \& Pandey, June 2011) stated that it's defined as a pleasant emotional case coming from the job appraisal, its describes effective response to your job and the attitudes the important of job satisfaction attribute that frequently measured by companies through rating scale, employee's reaction to their work.

(Ramayah et al., 2001) indicated the important of job satisfaction for reason moral responsibility and positive contributions for satisfied workers. Also, (Aziri, B., 2011) has considered job satisfaction is one of the factors that linking to effectiveness and efficiency of the organization, and the modern managerial paradigm ask for employees rights and needs, the personal desires is an indicator about the importance of job satisfaction. When discuss job satisfaction this result to satisfied employee, and this mean he is a happy employee this define that happy employee is a successful employee. 


\subsection{Emotional Intelligence and Job Satisfaction}

Emotional intelligence have the main affect on farther more in activities in the work place, the way employee work, inability or ability to work as a team, initiative and originality, nurturing talent, service delivery levels, client satisfaction and loyalty (Zeidner, Matthews, \& Roberts, 2004).

Job satisfaction can be defined as Inductor for emotional condition as a result from the characteristics and features of a work environment (Arches, 1991).

(Kumari \& Pandey, June 2011) argued that job satisfaction is an attitude but other researchers should clear distinguish the mean of cognitive evaluation that impact (emotion), behaviors and beliefs. The ability to manage your emotions and stress handling is another aspect of emotional intelligence that is important for success. In predicting employee success, many previous studies supported that emotional intelligence could also be conceder a factor in determining life success (Cherniss, 2001).

Some researchers have done research regarding EI and found that senior managers will perform job better than senior managers with low EI (Carmeli, 2003).

\subsection{Previous Studies}

Many studies analysis the effect of emotional intelligence on job satisfaction. (Psilopanagioti et al., 2012), (Taboli, 2013), (Zakieh Shooshtarian, 2013), (Sener, Demirel, \& Sarlak, 2009), (Fasihizadeh, 2012), (Gunavathy \& Ayswarya, 2011), (Simin Hosseinian, 2008), (Konstantinos Kafetsios A, 2008) argued that there is affect of emotional intelligence on job satisfaction. And, (Zainal, Nasurdin, \& Hoo, 2012) have argued that there some part of emotional intelligence impact like other emotion and regulation of emotion more than self emotion and use emotions.

(Jorfi et al., 2012) has exposed that women highly emotion intelligence and more concerned with people. (Marjanović \& Dimitrijević, 2013) they concluded that the current findings reinforced the use of intelligence traditional measures and the personality trait of emotional intelligence in predicting job related criteria, but encourage and prefer the assessment of trait of emotional intelligence for the purpose of predicting well-being.

(Siddiqui Razi Sultan 2013) they indicated that high score on trait of emotional intelligence individual could control and regulate their behavior in a way that could promote wellbeing, motivation level, job satisfaction, interpersonal relationship, quality work of life and retention time in an organization.

\section{Applied Study}

This secession includes the results of the statistical analysis and the study result.

\subsection{Test of the First Main Hypothesis}

$\mathrm{H}_{\mathrm{ol}}$ : There is no statistically significant affect for Emotional Intelligence elements on the Job satisfaction in the telecommunication companies.

To test this hypothesis the multiple regression analysis was conducted and the following table shows the results linked to that:

Table 2. Result of multiple regression analysis: regressing EI variables against JS

\begin{tabular}{ccccc}
\hline Variables & $\mathrm{R}$ & $\mathrm{R}^{2}$ & ANOVAF-Value & $\mathrm{Sig}$ \\
\hline EI elements & 0.571 & 0,326 & 16.451 & 0,00 \\
\hline
\end{tabular}

Table 2 shows the result of the multiple regression analysis that regress the three variables of EI together explained (32.6) percent of the variance, where $\left(\mathrm{R}^{2}=0.326, \mathrm{~F}=16.451\right.$, $\left.\mathrm{Sig}=0.000\right)$. Therefore, the Null hypothesis is rejected and the alternative hypothesis is accepted, which states that EI variables affect on the JS at $\mathrm{a}=0.05$.

\subsection{Test of the Sub Hypothesis}

$\mathrm{H}_{\mathrm{ol}-1:}$ There is no statistically significant affect for Well-being on the Job Satisfaction.

Ho1-2: There is no statistically significant affect for Self-control on the Job Satisfaction.

Ho1-3: There is no statistically significant affect for Emotionality on the Job Satisfaction.

To test these hypotheses, the regression analysis was conducted and the following table shows the results linked to that: 
Table 3. Result of coefficients regression analysis

\begin{tabular}{cccc}
\hline Variables & Beta coefficient & $\mathrm{T}$ & Sig \\
\hline Well-being & 0.271 & 1,826 & 0,000 \\
\hline Self- Control & 0.165 & 2.014 & 0.000 \\
\hline Emotionality & 0.158 & 2.110 & 0.034 \\
\hline
\end{tabular}

Table 3 includes the regression coefficients and calculated significance value in order to measure the affect of three construct of (EI) and the dependent variable (JS) within a confidence interval $=95 \%$ and a proposed significance level $=0.05$. The table indicates that a significant positive impact for the (Well-being) with the (JS) was found ( $\mathrm{Sig}=$ 0.000 , Beta $=0.271)$. Therefore, the Null hypothesis $(1-1)$ is rejected and the alternative hypothesis is accepted, which states that (Well-being) variable affect on the JS at $a=0.05$. Next, the table indicates that a significant positive impact for the (Self-control) with the (JS) was found $(\mathrm{Sig}=0.000$, Beta $=0.165)$. Therefore, the Null hypothesis $(1-2)$ is rejected and the alternative hypothesis is accepted, which states that (Self-control) variable affect on the JS at $\mathrm{a}=$ 0.05. Thirdly, the table also indicates that a significant positive impact for the (Emotionality) with the (JS) was found $(\mathrm{Sig}=0.034$, Beta $=0.158)$. Therefore, the Null hypothesis $(1-3)$ is rejected and the alternative hypothesis is accepted, which states that (Emotionality) variable affect on the JS at $\mathrm{a}=0.05$.

\section{The Conclusions of the Study}

In this study, the research aimed to find the impact of emotional intelligence through their elements on the job satisfaction for the employees in the Jordanian telecommunication sector and the out comes the following from this conclusion:

1). There is positive effect of the elements of emotional intelligence on the job satisfaction in the sector of the Jordanian telecommunication companies.

2). There is a positive effect of the well-being on the job satisfaction in the sector of the Jordanian telecommunication companies.

3). There is a positive effect of the self-control on the job satisfaction in the sector of the Jordanian telecommunication companies.

4). There is a positive effect of the emotionality on the job satisfaction in the sector of the Jordanian telecommunication companies.

\section{The Recommendation of the Study}

1). Create a clear understanding of emotional intelligence with senior management and work to spread among employees in the organization.

2). Use the elements of emotional intelligence among employees to create more job satisfaction for them.

3). Help employees to use of emotional intelligence to increase their productivity

4). Give a clear understanding of the employees about emotional intelligence and its impact on them.

5). Create a clear strategy to deal with the employees and make deepen understanding about emotional intelligence and its impact in increase of job satisfaction among employees.

6). Focus on increasing job satisfaction for employees through the provision of work requirement in the organization.

7). Utilization of human resources in a better exploitation of the organization by increasing job satisfaction.

8). Encourage employees to develop their skills and scientific and practical abilities by increasing their job satisfaction

9). Adopt creative and innovative ideas that contribute to the achievement of satisfaction among employees.

10). Focus on create more activities that contribute to the promotion and spread of emotional intelligence among employees. 
11). Give a clear image of the vision and mission and objectives of the organization to employees with an explanation of the advantages and benefit when using emotional intelligence.

12). Use the organizational justice in all actions within the organization which lead to deepen satisfaction among employees.

13). Participation of employees in decision-making in organization for the promotion of job satisfaction among employees.

\section{References}

Arches, J. (1991). Social structure, burnout, and job satisfaction. Soc Work, 36(3), 202-206.

Bar-On, R. (2006). The Bar-On model of emotional-social intelligence (ESI). Colegio Oficial de Psicológicas de Asturias, 18.

Boyle, G.J., Matthews, G., \& Saklofske, D.H. (2008). The SAGE handbook of personality theory and assessment. Los Angeles, Calif.: SAGE Publications.

Brackett, M.A., Mayer, J.D., \& Warner, R.M. (2004). Emotional intelligence and its relation to everyday behaviour. Personality and Individual Differences, 36(6), 16. Retrieved from http://www.jarwan-center.com

Carmeli, A. (2003). The relationship between emotional intelligence and work attitudes, behaviour and outcomes. Journal of Managerial Psychology, 18.

Carter, P. (2005). The IQ Workout Series:THE COMPLETE BOOK OF INTELLIGENCE TESTS. Southern Gate: John Wiley\&Sons Ltd, The Atrium, Southern Gate, Chichester, West Sussex PO19 8SQ, England.

Cherniss, C. (2001). Emotional Intelligence: What it is and Why it Matters. Emotional Intelligence: What it is and Why it Matters.

Cherniss, C. (2010). Emotional Intelligence: TowardClarification of a Concept. Industrial and Organizational Psychology, 3(2). http://dx.doi.org/10.1111/j.1754-9434.2010.01231.x

DE KOK, C. (2013, January). Happiness at Work: Are Job Satisfaction, Job Self-Efficacy and Trait Emotional Intelligence Related? (Master of Arts), University of South Africa, South Africa.

Fasihizadeh, N., Oreyzi, H., \& Nouri, A. (2012). Investigation of positive affect and emotional intelligence effect on Job satisfaction among oil refinery personnel of Isfahan. Institute of Interdisciplinary Business Research, 4(2), 32 .

Greenspan, S.I. (1989). Emotional intelligence. Learning and education: Psychoanalytic perspectives, 35.

Gunavathy, J., \& Ayswarya, R. (2011). Emotional Intelligence and Job Satisfaction as Correlates of Job Performance - A Study among Women Employed in the Indian Software Industry. Institute of Management Technology, $15(1 / 2), 8$.

Jorfi, H., Fauzy Bin Yacco, H., \& Md Shah, I. (2012). Role of Gender in Emotional Intelligence: Relationship among Emotional Intelligence, Communication Effectiveness and Job Satisfaction. International Journal of Management, 29(4), 8.

Konstantinos Kafetsios, A.L.A.Z. (2008). Emotional intelligence and job satisfaction: Testing the mediatory role of positive and negative affect at work. Personality and Individual Difference, 44, 11.

Kumari, G., \& Pandey, K.M. (2011, June). Job Satisfaction in Public Sector and Private Sector: A Comparison. International Journal of Innovation, Management and Technology, 2(3), 7.

Leuner, B. (1966). Emotionale Intelligenz und Emanzipation [Emotional intelligence and emancipation]. Praxis der Kinderpsychologie und Kinderpsychiatry, 15, 8.

Marjanović, Z.J., \& Dimitrijević, A.A. (2013). Emotional Intelligence as a Predictor of Job Related Criteria and Well-Being. Paper presented at the International Psychological Applications Conference and Trends 2013, Belgrade (Serbia).

Mayer, J., Salovey, P., \& Caruso, D.R. (2000). Models of Emotional Intelligence. Cambridge: Cambridge University Press.

Mayer J.D.S.P. (1997). What Is Emotional Intelligence? In Salovey, \& Sluter, D. (Eds.), Emotional Development and Emotional Intelligence: Implications for Educators. New York: New York: Basic Books. 
Payne, W.L. (1986). A study of emotion: Developing emotional intelligence, selfintegration, relating to fear, pain, and desire. Dissertation Abstracts International.

Petrides, K.V. (2001). A Psychometric Investigation into the Construct of Emotional Intelligence. London: University College London.

Petrides, K.V. (2009). Technical Manual for the Trait Emotional Intelligence Questionnaire (TEIQue). London: London Psychometric Laboratory.

Petrides, K.V., \& Furnham, A. (2000). On the dimensional structure of emotional intelligence. Personality and Individual Differences, 29(2). http://dx.doi.org/10.1016/S0191-8869(99)00195-6

Petrides, K.V., \& Furnham, A. (2001). Trait emotional intelligence: psychometric investigation with reference to established trait taxonomies. European Journal of Personality, 15(6), 24. http://dx.doi.org/10.1002/per.416

Petrides, K.V., \& Furnham, A. (2006). The Role of Trait Emotional Intelligence in a Gender-Specific Model of Organizational Variables1. Journal of Applied Social Psychology, 36(2), 18.

Petrides, K.V., Furnham, A., \& Mavroveli, S. (2007). Trait Emotional Intelligence Moving Forward in the Field of EITrait Emotional Intelligence.

Psilopanagioti, A., Anagnostopoulos, F., Mourtou, E., \& Niakas, D. (2012). Emotional intelligence, emotional labor, and job satisfaction among physicians in Greece. BMC Health Serv Res, 12, 463. http://dx.doi.org/10.1186/1472-6963-12-463

Sener, E., Demirel, O., \& Sarlak, K. (2009). The effect of the emotional intelligence on job satisfaction. Stud Health Technol Inform, 146, 710-711.

Siddiqui Razi Sultan, H.A. (2013). Impact of Emotional Intelligence on EmployeesTurnover Rate in FMCG Organizations. Pakistan Journal of Commerce and Social Sciences, 7(2), 394-404.

Simin Hosseinian, S.M.Y., Zahraie, S., \& Fathi-Ashtiani, A. (2008). Emotional intelligence and job satisfaction. Journal of Applied Sciences, 8(5), 4.

Taboli, H. (2013). Job Satisfaction as a Mediator in Relationship between Emotional Intelligence, Organizational Commitment in Employees' Kerman Universities. lifesciencesite.com, 10(1), 8. Retrieved from http://www.lifesciencesite.com/lsj/life1001/001_11485life1001_1_8.pdf

van Zyl, C.J.J., \& de Bruin, K. (2012. Dec.). The relationship between mixed model emotional intelligence and personality. South African Journal of Psychology, 42(4), 11.

Weiss, H.M. (2002). Deconstructing job satisfaction: Separating evaluations, beliefs and affective experiences. Human Resource Management Review, 12(2), 22. http://dx.doi.org/10.1016/S1053-4822(02)00045-1

Zainal, S.R.M., Nasurdin, A.M., \& Hoo, Q.C. (2012). The Role of Emotional Intelligence towards the career success of Hotel. International Conference on Economics, Business and ManagementIPEDR, 22, 6.

Zakieh Shooshtarian, F.A., \& Aminilari, M. (2013). The Effect of Labor's Emotional Intelligence on Their JobSatisfaction, Job Performance and Commitment. Iranian Journal of Management Studies, 6(1), 17.

Zeidner, M., Matthews, G., \& Roberts, R.D. (2004). Emotional Intelligence in the Workplace: A Critical Review. Applied Psychology: An International Review, 53(3). 